\title{
BMJ Open Trends in end digit preference for blood pressure and associations with cardiovascular outcomes in Canadian and UK primary care: a retrospective observational study
}

\author{
Michelle Greiver, ${ }^{1,2,3}$ Sumeet Kalia, ${ }^{3}$ Teja Voruganti, ${ }^{4}$ Babak Aliarzadeh, ${ }^{3}$ \\ Rahim Moineddin, ${ }^{3,5}$ William Hinton, ${ }^{6}$ Martin Dawes, ${ }^{7}$ Frank Sullivan, ${ }^{8}$ \\ Saddaf Syed, ${ }^{3}$ John Williams, ${ }^{6}$ Simon de Lusignan ${ }^{6,9}$
}

To cite: Greiver M, Kalia S, Voruganti T, et al. Trends in end digit preference for blood pressure and associations with cardiovascular outcomes in Canadian and UK primary care: a retrospective observational study. BMJ Open 2019;9:e024970. doi:10.1136/ bmjopen-2018-024970

- Prepublication history and additional material for this paper are available online. To view these files, please visit the journal online (http://dx.doi. org/10.1136/bmjopen-2018024970).

Received 24 June 2018 Revised 16 December 2018 Accepted 18 December 2018

Check for updates

(C) Author(s) (or their employer(s)) 2019. Re-use permitted under CC BY-NC. No commercial re-use. See rights and permissions. Published by BMJ.

For numbered affiliations see end of article.

Correspondence to Dr Michelle Greiver; mgreiver@rogers.com

\section{ABSTRACT}

Objectives To study systematic errors in recording blood pressure (BP) as measured by end digit preference (EDP); to determine associations between EDP, uptake of Automated Office BP (AOBP) machines and cardiovascular outcomes. Design Retrospective observational study using routinely collected electronic medical record data from 2006 to 2015 and a survey on year of AOBP acquisition in Toronto, Canada in 2017.

Setting Primary care practices in Canada and the UK. Participants Adults aged 18 years or more.

Main outcome measures Mean rates of EDP and change in rates. Rates of EDP following acquisition of an AOBP machine. Associations between site EDP levels and mean BP. Associations between site EDP levels and frequency of cardiovascular outcomes.

Results 707227 patients in Canada and 1558471 patients in the UK were included. From 2006 to 2015, the mean rate of $\mathrm{BP}$ readings with both systolic and diastolic pressure ending in zero decreased from $26.6 \%$ to $15.4 \%$ in Canada and from $24.2 \%$ to $17.3 \%$ in the UK. Systolic BP readings ending in zero decreased from $41.8 \%$ to $32.5 \%$ in the 3years following the purchase of an AOBP machine. Sites with high EDP had a mean systolic BP of $2.0 \mathrm{~mm} \mathrm{Hg}$ in Canada, and $1.7 \mathrm{~mm} \mathrm{Hg}$ in the UK, lower than sites with no or low EDP. Patients in sites with high levels of EDP had a higher frequency of stroke (standardised morbidity ratio (SMR) $1.15,95 \% \mathrm{Cl} 1.12$ to 1.17), myocardial infarction (SMR $1.16,95 \% \mathrm{Cl} 1.14$ to 1.19) and angina (SMR $1.25,95 \% \mathrm{Cl} 1.22$ to 1.28 ) than patients in sites with no or low EDP.

Conclusions Acquisition of an AOBP machine was associated with a decrease in EDP levels. Sites with higher rates of EDP had lower mean BPs and a higher frequency of adverse cardiovascular outcomes. The routine use of manual office-based BP measurement should be reconsidered.

\section{INTRODUCTION}

High blood pressure (BP) is a leading cause of increased morbidity and early mortality in adults. ${ }^{1}$ BP should be routinely measured as part of clinical encounters. ${ }^{2}$ However, there
Strengths and limitations of this study

- The study found that the purchase of Automated Office BP (AOBP) machines by primary care offices was followed by more accurate blood pressure (BP) measurement.

- Offices with less accurate BP measurement (more end digit preference) rounded BP readings down.

- These offices also had higher frequencies of adverse cardiovascular outcomes.

- The survey of AOBP machine purchase was done only in Ontario; we infer that the purchase of an AOBP machine was associated with less end digit preference elsewhere.

are long-standing concerns about the precision and accuracy of BP measurement in practice. ${ }^{34}$ There is evidence that measuring BP manually, using an aneroid or mercury column sphygmomanometer, is associated with systematic recording errors including end digit preference (EDP) and observer bias. ${ }^{5}$ EDP means that the observer rounds off the last digit ${ }^{6}$; for example, BPs end in zero for up to $60 \%$ of records instead of the expected $10 \% .^{78}$ Observer bias means that $\mathrm{BP}$ is adjusted towards a preferred level (rounding up or rounding down). ${ }^{8}$ These issues may lead to errors in the diagnosis and treatment of hypertension. ${ }^{9}$

Automated Office BP (AOBP) measurement uses a machine to record and report the numerical values of systolic and diastolic BPs on a digital display. ${ }^{10}$ Three to six recordings are done; the initial reading is discarded and the remaining readings are averaged. ${ }^{11}$ Research suggests that EDP is reduced as a result of this method. ${ }^{911}$ AOBP is comparable to the gold standard of 24 hours 
automated home BP monitoring. ${ }^{12}$ Canadian and European hypertension guidelines now recommend AOBP as the preferred method for office-based measurement of $\mathrm{BP}^{2}{ }^{13}$ but have not made a recommendation to discontinue the routine use of manual BP measurement.

There is evidence that AOBP machines are increasingly used in primary care; it has been reported that $>10000$ AOBP machines are currently in use in Canada. ${ }^{11}$ In a recent Canadian survey, $43 \%$ of family physicians reported using AOBP to screen for hypertension. ${ }^{14}$ However, the proportion of office BP measurements done using AOBP when machines are available in an office is not known. Changes in the proportion of BPs with EDP could serve as a marker of increasing use of AOBP in primary care practice, although this requires validation.

Accurate measurement is essential for BP control. There is a need to quantify systematic BP measurement errors in primary care, consider these in the context of changing AOBP use and estimate the effects of errors on cardiovascular outcomes affected by BP control.

The objectives of this study were therefore to (1) report the EDP levels with respect to patient-level and provider-level characteristics, (2) examine the changes in EDP with AOBP uptake in offices, (3) quantify prevalence and trends in systematic recording errors in BP recording and (4) determine associations between EDP and cardiovascular outcomes.

\section{METHODS}

We used a repeated cross-sectional observational design. We applied the STrengthening the Reporting of OBservational studies in Epidemiology checklist for reporting observational studies. ${ }^{15}$

\section{Settings and data sources}

\section{Canada}

The Canadian Primary Care Sentinel Surveillance Network (CPCSSN) database was used for this study. ${ }^{16}$ CPCSSN is Canada's largest electronic medical record (EMR)-based chronic disease surveillance system ${ }^{16}$ and includes data collected from 11 primary care practice-based research networks in 8 of Canada's 13 provinces and territories. Consenting family physicians and other primary care providers participating in CPCSSN contribute de-identified EMR data to regional network repositories; patients can opt-out if they choose to do so. Data from all participating networks are collected every 6 months and aggregated in a single central database. ${ }^{16}$ The distribution of the CPCSSN patient population is reasonably similar to that of Canadian census. ${ }^{17}$

We used EMR data extracted and processed using procedures previously described. ${ }^{16}$ CPCSSN case definition algorithms have been validated against chart audits for eight chronic conditions (diabetes, hypertension, chronic obstructive pulmonary disease, depression, osteoarthritis, dementia, parkinsonism and epilepsy) in multiple sites across Canada. ${ }^{18}$
UK

We repeated the analyses using the Royal College of General Practitioners (RCGP) Research and Surveillance Centre (RSC) database for the UK. This is one of Europe's oldest primary care sentinel networks. ${ }^{6}$ It has been reported that the RCGP RSC has data of high quality for chronic disease, including diabetes ${ }^{6}$ and cardiovascular outcomes. ${ }^{19}$

The RCGP RSC data are extracted twice weekly from the EMRs of $>150$ representative general practices (groups of physicians practising in the same location) in England, covering a population of over 1.5 million patients and $3 \%$ of the population. A comparison of RCGP RSC practices with national pay-for-performance data, prescribing data and the quality and outcomes framework suggests that data are representative of the national population in terms of age and gender of the population, ethnicity and deprivation. ${ }^{6}$ RCGP RSC includes comprehensive recording of cardiovascular risk factors and outcomes. ${ }^{20}$

\section{Study population}

We used routinely collected clinical EMR data from primary care clinics across Canada and the UK. These data were extracted in Canada as of 30 June 2016 and in the UK as of 31 December 2016. We examined BP measurements taken between 1 January 2006 and 31 December 2015 in the CPCSSN database and in the RCGP RSC database. We included all patients who were at least 18 years of age as of BP measurement date. We identified patient characteristics that may influence BP and its measurement. Patient variables included: age, sex, presence of hypertension and/or diabetes, body mass index (BMI), use of hypertensive medications. We recorded the total number of patients included for each site; a site was a group of physicians practising in the same location.

\section{Statistical analysis}

We examined the proportions of BPs ending in each digit in Canada and UK. We used the entire collection of $\mathrm{BP}$ records in both databases to estimate the unadjusted frequency of last digit zero for both systolic and diastolic BPs with respect to patient, site and temporal characteristics.

Since many patients had BP recorded multiple times with irregular visit to primary care between January 2006 and December 2015, we chose to discard excess information using a sampling mechanism..$^{21}$ In particular, we generated 1000 independent replicates using the stratified sampling without replacement where one BP measurement was randomly chosen for a given patient. Logistic regression was performed on 1000 independently sampled replicates of the CPCSSN and RCGP RSC database. The ORs were estimated using the mean and $95 \%$ CIs were estimated using the $2.5 \%$ and $97.5 \%$ percentiles of 1000 bootstrap estimates. ${ }^{22}$ All covariates in the regression model were held constant to their latest value for each patient with respect to the study follow-up. For example, the most recent information on BMI or 
the diagnosis of diabetes or hypertension medication was used for each patient. We adjusted for patient variables that may influence BP or its measurement: age, sex, presence of hypertension and/or diabetes, BMI, use of hypertensive medications. We also adjusted for the size of the practice panels, as this may influence quality of care. Finally, we adjusted for year of measurement as EDP levels changed over time.

To correlate rates of EDP with AOBP uptake, we conducted a subgroup analysis using data from the University of Toronto Practice-Based Research Network (UTOPIAN). UTOPIAN is the largest network in CPCSSN, with about $25 \%$ of data in the national database; it includes providers and patients from Toronto and surrounding areas in southern Ontario, Canada. We collected data on AOBP use from UTOPIAN practices using a survey, shown in online supplementary material. We contacted office representatives through email/ phone and asked them whether there was an AOBP in the office and when it was purchased. Office representatives were also asked to estimate how often BPs were done with the machine in the past year.

Responses were linked with EMR-based BP measurements for each site and the linked data were used for the subgroup analysis. We examined the association between length of time the machine was present in the office and the rate of EDP, as well as association between EDP for 2015 and the self-reported level of use in the past year.

We implemented unsupervised cluster analysis to categorise primary care sites into three groups for each year. ${ }^{23}$ The three groups were labelled as: (1) high EDP, (2) medium EDP and (3) low or no EDP. Practices were clustered by presence of less commonly recorded end digits $(1,3,7,9)$ for both systolic BP and diastolic BP; $40 \%$ of BPs would be expected to end in one of those digits. To control for excessive noise in the data, we chose to exclude the sites with $<1000 \mathrm{BP}$ measurements within a year.

Since the changes in uncommon end digits $(1,3,7,9)$ may be confounded by the recruitment of new sites over time or changes in patient populations within sites, the proportion of recording uncommon digits was reported for each measurement year, giving a rate of EDP per site per year. The similarity between all pairs belonging to the same cluster was computed using the Ward score. ${ }^{24}$ We examined the mean systolic BP among patients with and without hypertension and diabetes using the classification obtained from the cluster analysis.

We estimated the annual frequency of three cardiovascular events (myocardial infarction, angina, stroke) using UK data; these conditions have not yet been validated in the Canadian data in CPCSSN. We compared sites with high EDP in each year against sites with low or no EDP for the same year. The denominator was defined as the total number of patients who had at least one BP recorded within each year of interest for each group. The numerator was defined as the total number of patients included in the denominator with a cardiovascular event within the same year. Patients with a cardiovascular event were censored in subsequent years. We estimated the standardised morbidity ratio for each condition in groups with high EDP compared with groups with low or no EDP.

The study received a favourable opinion from the RCGP RSC study review panel. CPCSSN has received REB approval from Health Canada, and each host university for all participating practice-based research networks. All participating primary care providers have provided written informed consent for the collection and analysis of their EMR data. All statistical analyses were conducted using SAS software, V.9.4 M4 (SAS Institute).

\section{Patient and public involvement}

No patients were involved in setting the research question or the outcome measures, nor were they involved in developing plans for design or implementation of the study. We received input into the study from patient and public representatives who commented on the relevance of the question and the potential impact of the research on outcomes.

\section{RESULTS}

Data from 181 sites and 707227 patients in CPCSSN were included; there were 5.5 million BP records. Data from 164 sites and 1558471 patients in the RCGP RSC database were included; there were 13.4 million BP records. Each patient was counted once, regardless of the number of BPs and number of years in which they had a BP recorded. The most frequently recorded end digit was zero while the least frequent end digits were 1, 3, 7 and 9 (table 1, figure 1).

Patient and site characteristics and trends in levels of EDP are shown in table 2. The frequency of last digit zero for both systolic and diastolic BP decreased by $11.2 \%$ in Canada and by $6.9 \%$ in the UK from 2006 to 2015. Table 3 describes the adjusted ORs of recording zero as the last digit of systolic and diastolic BP. The ORs of last digit zero

Table 1 Frequency of end digits for systolic and diastolic blood pressures

\begin{tabular}{lccccc}
\hline & \multicolumn{3}{l}{ Canada } & & \multicolumn{1}{l}{ UK } \\
\cline { 2 - 3 } \cline { 5 - 6 } End digits & $\begin{array}{l}\text { Systolic } \\
\text { BP (\%) }\end{array}$ & $\begin{array}{l}\text { Diastolic } \\
\text { BP (\%) }\end{array}$ & & $\begin{array}{l}\text { Systolic } \\
\text { BP (\%) }\end{array}$ & $\begin{array}{l}\text { Diastolic } \\
\text { BP (\%) }\end{array}$ \\
\hline 0 & 32.4 & 35.9 & 33.8 & 34.0 \\
\hline 1 & 3.6 & 3.7 & 4.5 & 4.5 \\
\hline 2 & 13.1 & 10.9 & 10.3 & 9.6 \\
\hline 3 & 3.8 & 3.8 & 4.8 & 4.7 \\
\hline 4 & 10.4 & 10.0 & 9.1 & 9.3 \\
\hline 5 & 7.2 & 6.8 & 8.3 & 8.2 \\
\hline 6 & 9.3 & 8.9 & 8.5 & 8.4 \\
\hline 7 & 3.9 & 3.8 & 4.9 & 4.8 \\
\hline 8 & 12.6 & 12.4 & 11.2 & 11.6 \\
\hline 9 & 3.8 & 3.4 & 4.8 & 4.9 \\
\hline
\end{tabular}



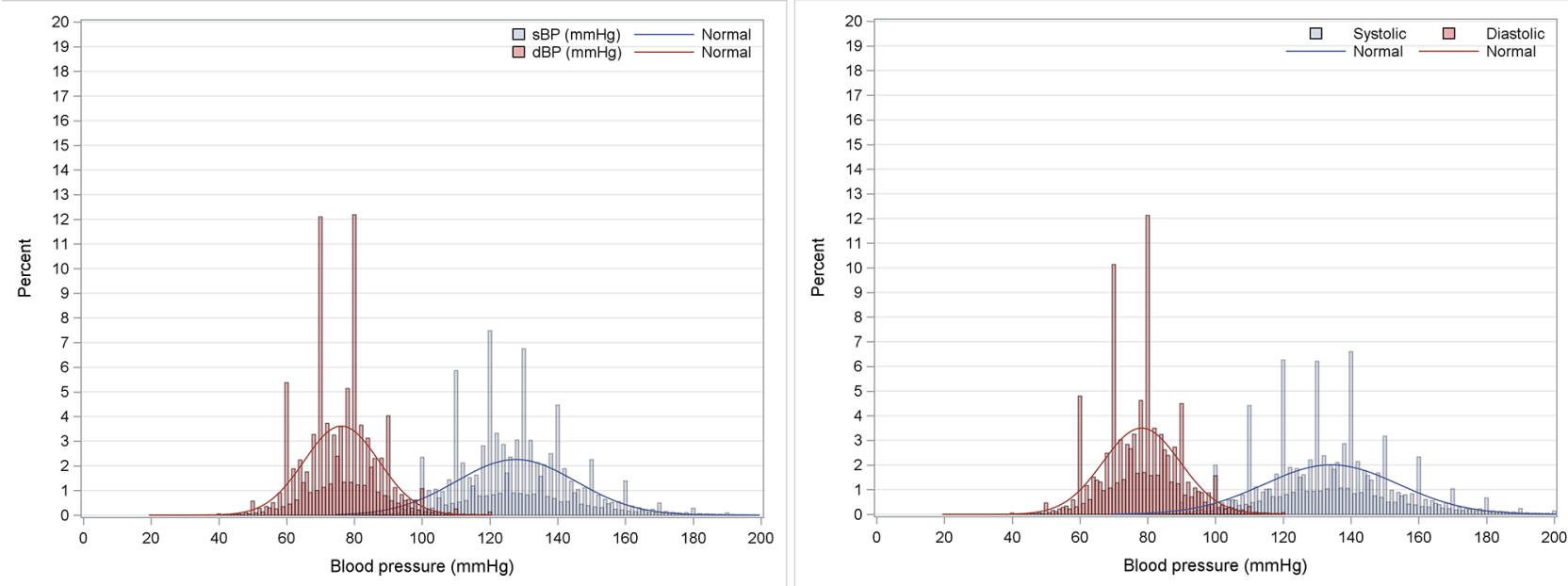

Figure 1 Histogram of systolic (sBP) and diastolic blood pressure (dBP) in Canada and the UK.

were greater among female patients (CPCSSN: OR=1.10, 95\% CI 1.09 to 1.11 ; RCGP: OR=1.16, 95\% CI 1.15 to 1.16 ). Patients with hypertension were less likely to have EDP than patients without hypertension (CPCSSN: OR=0.89, 95\% CI 0.88 to 0.91 ; RCGP RSC: OR $=0.79,95 \%$ CI 0.78 to $0.80)$. Patients with diabetes were less likely to have EDP in Canada ( $\mathrm{OR}=0.98,95 \% \mathrm{CI} 0.96$ to 0.99 ) but were more likely to have this in the UK $(\mathrm{OR}=1.025,95 \%$ CI 1.01 to 1.04). ORs of EDP decreased as BMI levels increased in Canada but not in the UK.

Sixty-five UTOPIAN sites were surveyed; 55 (85\%) responded. Ninety-three per cent of the UTOPIAN sites reported having at least one AOBP machine in the practice; most were bought between 2007 and 2014. Even when AOBP machines were present, most offices reported still using manual measurement. There was a reduction of $9.3 \%$ (from $41.7 \%$ to $32.5 \%$ ) in the proportion of systolic BPs ending in zero within 3 years of adopting the AOBP machines $(95 \% \mathrm{CI}-8.9 \%$ to $-9.8 \%)$. Family practices who reported rarely or never using AOBP machines had higher EDP than those reporting at least some use of AOBP (figure 2).

As illustrated in figure 3, cluster analyses were used to find the optimal decision boundaries to classify sites into high EDP, medium EDP, low or no EDP for Canada and the UK. Table 4 provides the number and percentage of sites in each group. In 2006, there was only one Canadian site $(3.6 \%)$ with low or no EDP while in the UK, 61 sites $(38.4 \%)$ were in this group. Sites exhibiting high EDP decreased by $47.7 \%$ in Canada and by $15.1 \%$ in the UK from 2006 to 2015. In contrast, the proportion of sites classified as having low or no EDP increased by $22.9 \%$ in Canada and $12.8 \%$ in the UK.

The mean systolic BP by EDP group is shown in table 5 . Sites with low or no EDP had a higher mean systolic BP than sites with high EDP $(1.97 \mathrm{~mm} \mathrm{Hg}$ in Canada; $1.76 \mathrm{~mm} \mathrm{Hg}$ in the UK). When stratified by presence or absence of hypertension or diabetes, the direction was similar with differences ranging from 0.9 to $2.4 \mathrm{~mm} \mathrm{Hg}$.
As shown in figure 4, we observed a higher mean frequency of myocardial infarction $(0.40 \%, 95 \%$ CI 0.39 to 0.41$)$, stroke $(0.64 \%, 95 \%$ CI 0.63 to 0.65$)$ and angina $(0.42 \%, 95 \%$ CI 0.41 to 0.43$)$ in sites with high EDP as compared with sites with low or no EDP: $0.34 \%$ (95\% CI 0.33 to 0.35 ), $0.56 \%$ (95\% CI 0.55 to 0.57 ) and $0.33 \%$ (95\% CI 0.32 to 0.34 ), respectively. Table 6 provides the standardised morbidity ratio; this was higher for all three conditions for sites with high EDP compared with sites with low or no EDP.

\section{DISCUSSION}

We found significant levels of systematic recording errors in BP measurement in the UK and Canada; these decreased over time. There was an association between the length of time an AOBP machine was present in an office and a decrease in EDP. Higher rates of EDP, and presumably more use of manual $\mathrm{BP}$ recording in those sites, appeared to be associated with rounding down of BPs and a higher frequency of adverse cardiovascular outcomes.

Our study found decreasing rates of in EDP; there have been increasingly strong guideline recommendations to switch to AOBP. ${ }^{25}$ While a recent survey found that almost half of Canadian physicians reported using AOBP to screen for hypertension, ${ }^{14}$ most offices in this study reported continued use of manual BP measurement for some patients even when an AOBP machine was present in the office. We found a gradual decrease in EDP associated with the length of time that AOBP has been present in the office, indicating that physicians and sites may be increasingly accustomed to its routine use for measurement.

European Guidelines recommending adoption of AOBP were associated with a large decrease in recorded BPs ending in zero in the UK, from $71.2 \%$ in 1996-1997 to $36.7 \%$ in $2005-2006 .{ }^{26}$ UK studies based on the Quality Improvement in Chronic Kidney Disease trial ${ }^{27}$ have 
Table 2 Patient/site characteristics and BP measurements ending in zero for both systolic BP and diastolic BP in Canada (CPCSSN) and the UK (RCGP RSC database)

\begin{tabular}{|c|c|c|c|c|c|c|}
\hline \multirow[b]{2}{*}{ Characteristics } & \multicolumn{3}{|l|}{ Canada } & \multicolumn{3}{|l|}{ UK } \\
\hline & $\begin{array}{l}\text { Number of patients } \\
\text { (\% of patients) }\end{array}$ & $\begin{array}{l}\text { Number of BPs (\% } \\
\text { of BPs) }\end{array}$ & $\begin{array}{l}\text { Number of BPs } \\
\text { with both systolic } \\
\text { and diastolic BP } \\
\text { ending in zero (\% } \\
\text { with both ending } \\
\text { in zero) }\end{array}$ & $\begin{array}{l}\text { Number of patients } \\
\text { (\% of patients) }\end{array}$ & $\begin{array}{l}\text { Number of BPs ( } \% \\
\text { of BPs) }\end{array}$ & $\begin{array}{l}\text { Number of BPs } \\
\text { with both systolic } \\
\text { and diastolic BP } \\
\text { ending in zero (\% } \\
\text { with both ending } \\
\text { in zero) }\end{array}$ \\
\hline Total & 707227 & 5503663 & 1044031 (19.0\%) & 1558471 & 13424678 & 2674497 (19.9\%) \\
\hline \multicolumn{7}{|l|}{ Age (years) } \\
\hline $18-39$ & $189254(26.8)$ & $816136(14.8)$ & 165025 (20.2) & $531632(34.1)$ & 2330344 (17.4) & $538786(23.1)$ \\
\hline $40-59$ & 247771 (35) & $1534126(27.9)$ & 292435 (19.1) & 498272 (32.0) & 3298174 (24.6) & $631260(19.1)$ \\
\hline $60-79$ & $201364(28.5)$ & 2115655 (38.4) & 377724 (17.9) & $352483(22.6)$ & 4879583 (36.3) & $868894(17.8)$ \\
\hline $80+$ & $68838(9.7)$ & $1037716(18.9)$ & $208847(20.1)$ & $176084(11.3)$ & 2916577 (21.7) & $635557(21.8)$ \\
\hline \multicolumn{7}{|l|}{ Sex } \\
\hline $\begin{array}{l}\text { Underweight } \\
\text { (BMl<18.5) }\end{array}$ & $10233(1.4)$ & $70776(1.3)$ & $14649(20.7)$ & $44654(2.9)$ & 308481 (2.3) & $71234(23.1)$ \\
\hline $\begin{array}{l}\text { Normal weight } \\
(18.5-24.9)\end{array}$ & $170684(24.1)$ & $1177970(21.4)$ & $236883(20.1)$ & $560214(36.0)$ & $4071114(30.3)$ & $852192(20.9)$ \\
\hline $\begin{array}{l}\text { Overweight } \\
(25-29.9)\end{array}$ & $182141(25.8)$ & $1545777(28.1)$ & 283163 (18.3) & $446850(28.7)$ & 4412326 (32.9) & $842338(19.1)$ \\
\hline $\begin{array}{l}\text { Obesity class I } \\
(30-34.9)\end{array}$ & $101980(14.4)$ & $1013286(18.4)$ & 175781 (17.3) & 200761 (12.9) & 2421241 (18.0) & 455572 (18.8) \\
\hline $\begin{array}{l}\text { Obesity class II } \\
(35-39.9)\end{array}$ & $42235(6.0)$ & 468239 (8.5) & 77408 (16.5) & $71450(4.6)$ & $928259(6.9)$ & $176969(19.1)$ \\
\hline $\begin{array}{l}\text { Obesity class III } \\
(\geq 40)\end{array}$ & $27451(3.9)$ & 320682 (5.8) & $52327(16.3)$ & $37370(2.4)$ & $491533(3.7)$ & 96589 (19.7) \\
\hline No & $521719(73.8)$ & $2798712(50.9)$ & $557244(19.9)$ & 1322755 (84.9) & 7065547 (52.6) & $1532832(21.7)$ \\
\hline \multicolumn{7}{|l|}{$\begin{array}{l}\text { Hypertension } \\
\text { medications }\end{array}$} \\
\hline Yes & $125484(17.7)$ & 2704947 (49.1) & $395371(17.7)$ & $466800(30.0)$ & 8327009 (62.0) & $1571464(18.9)$ \\
\hline No & $581743(82.3)$ & 2798686 (50.9) & $648660(19.8)$ & 1091671 (70.1) & 5097669 (38.0) & $1103033(21.6)$ \\
\hline \multicolumn{7}{|l|}{ Practice site size } \\
\hline $\begin{array}{l}\text { First quartile } \\
\text { (smallest site) }\end{array}$ & $36363(5.1)$ & 249957 (4.5) & $63781(25.5)$ & $173610(11.1)$ & 1671387 (12.5) & $303084(18.1)$ \\
\hline Second quartile & $77776(11)$ & $584575(10.6)$ & 110411 (18.9) & $305460(19.6)$ & 2836288 (21.1) & 480604 (16.9) \\
\hline Third quartile & $156601(22.1)$ & $1156892(21.0)$ & $228521(19.8)$ & $416580(26.7)$ & 3774278 (28.1) & $846481(22.4)$ \\
\hline $\begin{array}{l}\text { Fourth quartile } \\
\text { (largest site) }\end{array}$ & $436487(61.7)$ & 3512209 (63.8) & 641318 (18.3) & 662821 (42.5) & 5142725 (38.3) & $1044328(20.3)$ \\
\hline \multicolumn{7}{|l|}{ Measurement year* } \\
\hline 2006 & $52168(7.4)$ & $121355(2.2)$ & 32335 (26.6) & 542695 (34.8) & $1347400(10.0)$ & $325843(24.2)$ \\
\hline 2007 & 81699 (11.6) & 183591 (3.3) & $49030(26.7)$ & $553033(35.5)$ & $1342979(10.1)$ & 303477 (22.6) \\
\hline 2008 & $125781(17.8)$ & $277858(5.0)$ & $72772(26.2)$ & $563222(36.1)$ & $1353092(10.1)$ & $288418(21.3)$ \\
\hline 2009 & $167345(23.7)$ & 368245 (6.7) & $94871(25.8)$ & $572940(36.8)$ & 1358664 (10.1) & $278829(20.5)$ \\
\hline 2010 & 213250 (30.2) & $531316(9.7)$ & $117612(22.1)$ & 580069 (37.2) & $1340279(10.0)$ & 266242 (19.9) \\
\hline
\end{tabular}


Table 2 Continued

\begin{tabular}{|c|c|c|c|c|c|c|}
\hline \multirow[b]{2}{*}{ Characteristics } & \multicolumn{3}{|l|}{ Canada } & \multicolumn{3}{|l|}{ UK } \\
\hline & $\begin{array}{l}\text { Number of patients } \\
\text { (\% of patients) }\end{array}$ & $\begin{array}{l}\text { Number of BPs ( } \% \\
\text { of BPs) }\end{array}$ & $\begin{array}{l}\text { Number of BPs } \\
\text { with both systolic } \\
\text { and diastolic BP } \\
\text { ending in zero ( } \% \\
\text { with both ending } \\
\text { in zero) }\end{array}$ & $\begin{array}{l}\text { Number of patients } \\
\text { (\% of patients) }\end{array}$ & $\begin{array}{l}\text { Number of BPs ( } \% \\
\text { of BPs) }\end{array}$ & $\begin{array}{l}\text { Number of BPs } \\
\text { with both systolic } \\
\text { and diastolic BP } \\
\text { ending in zero (\% } \\
\text { with both ending } \\
\text { in zero) }\end{array}$ \\
\hline 2011 & 263691 (37.3) & 615364 (11.2) & $125282(20.4)$ & 590921 (37.9) & 1354956 (10.1) & 257309 (19.0) \\
\hline 2012 & $299590(42.4)$ & 700903 (12.7) & 128192 (18.3) & 602642 (38.7) & 1347042 (10.0) & 249344 (18.5) \\
\hline 2013 & 332809 (47.1) & 813009 (14.8) & $133434(16.4)$ & 617073 (39.6) & 1366085 (10.2) & 246754 (18.1) \\
\hline 2014 & $360180(50.9)$ & 894350 (16.3) & $137181(15.3)$ & $612382(39.3)$ & 1325141 (9.9) & $235377(17.8)$ \\
\hline 2015 & 386541 (54.7) & 997642 (18.1) & $153322(15.4)$ & 594589 (38.2) & 1289040 (9.6) & 222904 (17.3) \\
\hline
\end{tabular}

${ }^{*}$ Considering repeated measurements of BP for each patient with respect to measurement year.

$\mathrm{BP}$, blood pressure; BMI, body mass index (weight in kg/height in $\mathrm{m}^{2}$ ); CPCSSN, Canadian Primary Care Sentinel Surveillance Network; RCGP, Royal College of General Practitioners; RSC, Research and Surveillance Centre.

Table 3 Adjusted ORs of recording zero as the last digit for both systolic and diastolic blood pressure by patient and site characteristics

\begin{tabular}{|c|c|c|c|c|c|c|c|c|}
\hline \multirow[b]{2}{*}{ Effect } & \multirow[b]{2}{*}{ Index group } & \multirow{2}{*}{$\begin{array}{l}\text { Reference } \\
\text { group }\end{array}$} & \multicolumn{3}{|c|}{ Canada } & \multicolumn{3}{|l|}{ UK } \\
\hline & & & OR & $95 \% \mathrm{Cl}$ & $P$ value & OR & $95 \% \mathrm{Cl}$ & $P$ value \\
\hline \multirow[t]{2}{*}{ Age (years) } & $18-39$ & $80+$ & 1.088 & 1.063 to 1.112 & $<0.001$ & 0.784 & 0.773 to 0.795 & $<0.001$ \\
\hline & $60-79$ & $80+$ & 0.942 & 0.923 to 0.963 & $<0.001$ & 0.783 & 0.772 to 0.794 & $<0.001$ \\
\hline Sex & Female & Male & 1.100 & 1.089 to 1.112 & $<0.001$ & 1.156 & 1.148 to 1.163 & $<0.001$ \\
\hline \multirow[t]{5}{*}{ BMI } & Underweight (BMI<18.5) & $\begin{array}{l}\text { Obesity class III } \\
(\mathrm{BMl}>40)\end{array}$ & 1.316 & 1.267 to 1.366 & $<0.001$ & 1.047 & 1.019 to 1.074 & 0.001 \\
\hline & Normal (BMI 18.5-24.9) & Obesity class III & 1.226 & 1.192 to 1.258 & $<0.001$ & 0.960 & 0.939 to 0.980 & $<0.001$ \\
\hline & Overweight (BMI 25-29.9) & Obesity class III & 1.135 & 1.104 to 1.166 & $<0.001$ & 0.947 & 0.926 to 0.966 & $<0.001$ \\
\hline & Obesity class I (BMI 30-34.9) & Obesity class III & 1.065 & 1.036 to 1.096 & $<0.001$ & 0.953 & 0.932 to 0.973 & $<0.001$ \\
\hline & $\begin{array}{l}\text { Obesity class II (BMI } \\
\text { 35-39.9) }\end{array}$ & Obesity class III & 1.008 & 0.978 to 1.040 & 0.618 & 0.967 & 0.943 to 0.992 & 0.007 \\
\hline \multirow[t]{3}{*}{ Practice site size } & First quartile (smallest site) & $\begin{array}{l}\text { Fourth quartile } \\
\text { (largest site) }\end{array}$ & 1.950 & 1.908 to 1.990 & $<0.001$ & 0.816 & 0.809 to 0.823 & $<0.001$ \\
\hline & Second quartile & $\begin{array}{l}\text { Fourth quartile } \\
\text { (largest site) }\end{array}$ & 1.075 & 1.058 to 1.094 & $<0.001$ & 0.893 & 0.885 to 0.900 & $<0.001$ \\
\hline & Third quartile & $\begin{array}{l}\text { Fourth quartile } \\
\text { (largest site) }\end{array}$ & 1.087 & 1.074 to 1.100 & $<0.001$ & 0.891 & 0.883 to 0.899 & $<0.001$ \\
\hline \multirow[t]{5}{*}{ Measurement year } & 2006 & 2015 & 1.910 & 1.833 to 1.990 & $<0.001$ & 1.647 & 1.625 to 1.668 & $<0.001$ \\
\hline & 2007 & 2015 & 1.923 & 1.857 to 1.989 & $<0.001$ & 1.473 & 1.451 to 1.494 & $<0.001$ \\
\hline & 2008 & 2015 & 1.840 & 1.790 to 1.895 & $<0.001$ & 1.376 & 1.357 to 1.396 & $<0.001$ \\
\hline & 2009 & 2015 & 1.858 & 1.815 to 1.903 & $<0.001$ & 1.321 & 1.300 to 1.341 & $<0.001$ \\
\hline & 2010 & 2015 & 1.582 & 1.548 to 1.617 & $<0.001$ & 1.257 & 1.238 to 1.275 & $<0.001$ \\
\hline
\end{tabular}

ORs were adjusted for patient age, sex, presence of hypertension and/or diabetes, BMI, use of hypertensive medications. ORs were also adjusted for the size of the practice panels and year of measurement.

$\mathrm{BMI}$, body mass index (weight in $\mathrm{kg} /$ height in $\mathrm{m}^{2}$ ). 

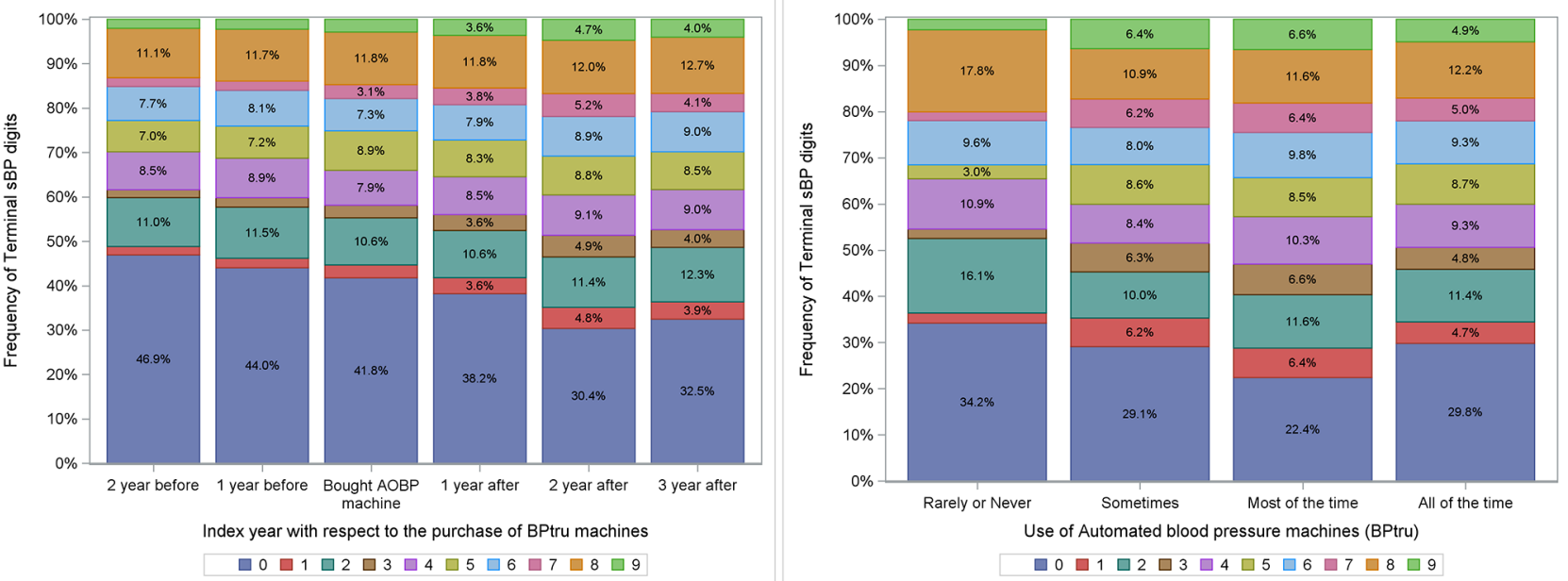

Figure 2 Impact of adopting automated office blood pressure machines on end digit preference for systolic blood pressure in Toronto.

shown reductions over time, presumably related to the progressive introduction of AOBP, although this assumption was not validated. ${ }^{28}$ In addition, there were changes in the patterns of recording odd versus even terminal digits. Another study in China also noted decreases in EDP over time. ${ }^{29}$ Implementation of AOBP in offices thus appears to be correlated with decreases in EDP. ${ }^{3726}$

The use of AOBP measurement resulted in lower readings than manual $\mathrm{BP}$ measurement (by $5-10 \mathrm{~mm} \mathrm{Hg}$ ) in a randomised controlled trial (RCT); AOBP readings agreed more closely with the gold standard of 24-hour BP measurement than manual BP readings. ${ }^{11}$ The introduction of AOBP should therefore be associated with a combination of lower rates of EDP (greater precision) and lower BP readings that are more consistent with the gold standard (greater accuracy). An observational study, however, found an association between higher rates of EDP and lower mean systolic BP, by $2-3 \mathrm{~mm} \mathrm{Hg} .{ }^{26} \mathrm{~A}$ study in the UK found that the change from manual to AOBP in primary care practices resulted in lower rates of EDP but no changes in mean BP. ${ }^{3}$

We found that sites with low or no EDP (those presumably using AOBP more consistently) had a mean BP that was close to $2 \mathrm{~mm} \mathrm{Hg}$ higher than those with greater rates of EDP (and presumably more use of manual BP in the practice) rather than the expected $5 \mathrm{~mm} \mathrm{Hg}$ lower. Therefore, observer errors associated with manual BP may have resulted in both rounding towards zero and systematically rounding down. Rounding down was observed for patients with diabetes and hypertension as well as for those without these conditions. This could potentially lead to underdiagnosis of hypertension and undertreatment of diagnosed hypertension. While there was no clinically significant association between measurement precision and presence of BP-lowering medication (ORs close to 1), our data do not permit us to determine
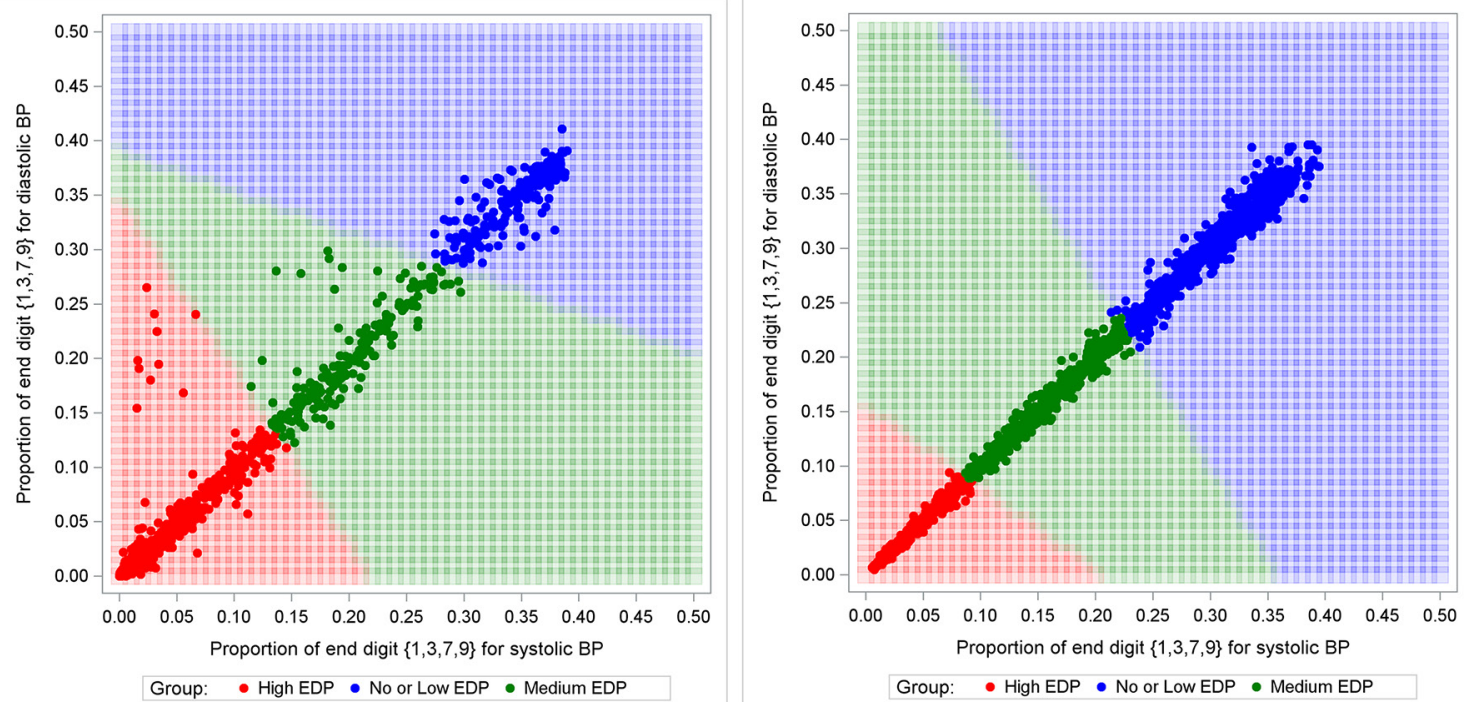

Figure 3 Proportions of systolic blood pressure (BP) and diastolic BP ending in 1, 3, 7 or 9 per practice site for each year of interest in Canada and the UK from 2006 to 2015. EDP, end digit preference. 
Table 4 Number and percentage of sites in each EDP group from 2006 to 2015

\begin{tabular}{|c|c|c|c|c|c|c|c|c|c|c|c|c|}
\hline \multirow[b]{3}{*}{ Year } & \multicolumn{6}{|c|}{ Canada } & \multicolumn{6}{|c|}{ UK } \\
\hline & \multicolumn{2}{|c|}{ Low or no EDP } & \multicolumn{2}{|c|}{ Medium EDP } & \multicolumn{2}{|c|}{ High EDP } & \multicolumn{2}{|c|}{ Low or no EDP } & \multicolumn{2}{|c|}{ Medium EDP } & \multicolumn{2}{|c|}{ High EDP } \\
\hline & $\mathbf{N}$ & Percent (\%) & $\mathbf{N}$ & Percent (\%) & $\mathbf{N}$ & Percent (\%) & $\mathbf{N}$ & Percent (\%) & $\mathbf{N}$ & Percent (\%) & $\mathbf{N}$ & Percent (\%) \\
\hline 2006 & 1 & 3.6 & 1 & 3.6 & 26 & 92.9 & 61 & 38.4 & 39 & 24.5 & 59 & 37.1 \\
\hline 2007 & 3 & 7.3 & 3 & 7.3 & 35 & 85.4 & 69 & 42.9 & 41 & 25.5 & 51 & 31.7 \\
\hline 2008 & 8 & 13.8 & 3 & 5.2 & 47 & 81.0 & 71 & 44.1 & 45 & 28.0 & 45 & 28.0 \\
\hline 2009 & 8 & 11.1 & 7 & 9.7 & 57 & 79.2 & 74 & 46.0 & 45 & 28.0 & 42 & 26.1 \\
\hline 2010 & 15 & 15.3 & 11 & 11.2 & 72 & 73.5 & 76 & 46.6 & 45 & 27.6 & 42 & 25.8 \\
\hline 2011 & 17 & 15.5 & 16 & 14.5 & 77 & 70.0 & 78 & 47.9 & 45 & 27.6 & 40 & 24.5 \\
\hline 2012 & 27 & 21.8 & 25 & 20.2 & 72 & 58.1 & 82 & 50.3 & 40 & 24.5 & 41 & 25.2 \\
\hline 2013 & 33 & 22.8 & 33 & 22.8 & 79 & 54.5 & 79 & 48.5 & 48 & 29.4 & 36 & 22.1 \\
\hline 2014 & 30 & 20.0 & 41 & 27.3 & 79 & 52.7 & 85 & 52.1 & 42 & 25.8 & 36 & 22.1 \\
\hline 2015 & 41 & 26.5 & 44 & 28.4 & 70 & 45.2 & 84 & 51.2 & 44 & 26.8 & 36 & 22.0 \\
\hline
\end{tabular}

EDP, end digit preference.

whether more precise measurement was associated with medication intensification through increase in dosage or addition of more medications. This could benefit from additional research.

A possible explanation for the observation of rounding down is provided by prospect theory, used in behavioural economics, which describes decisions made under conditions of uncertainty. Negative perceptions about possible risks (or risk aversion) outweigh positive perceptions about possible gains. ${ }^{30}$ There may be a behavioural bias towards rounding down; this may avoid perceived risks associated with adding more medications with less emphasis on gains from cardiovascular outcome prevention.

A large cluster RCT (Cardiovascular Health Awareness Program (CHAP)) documented improved management of hypertension in communities randomised to the intervention. This consisted of more accurate AOBP-based measurement in pharmacies with forwarding of abnormal BP results to family physicians. ${ }^{31}$ The CHAP intervention resulted in a significant decrease in hospitalisations due to cardiovascular disease (myocardial infarction, stroke, heart failure) ${ }^{31}$ In that trial, there was an improvement

Table 5 Mean sBP by EDP group

\begin{tabular}{|c|c|c|c|c|c|c|c|}
\hline & & \multicolumn{3}{|c|}{ CPCSSN database (Canada) } & \multicolumn{3}{|c|}{ RCGP RSC database (UK) } \\
\hline & & $\begin{array}{l}\text { No. of BP } \\
\text { measurements }\end{array}$ & $\begin{array}{l}\text { Mean sBP in } \\
\mathrm{mm} \mathrm{Hg}\end{array}$ & SD & $\begin{array}{l}\text { No. of BP } \\
\text { measurements }\end{array}$ & $\begin{array}{l}\text { Mean sBP in } \\
\mathrm{mm} \mathrm{Hg}\end{array}$ & SD \\
\hline \multirow[t]{3}{*}{ All patients } & Low or no EDP & 1151795 & 128.21 & 18.92 & 5618800 & 135.05 & 20.09 \\
\hline & High EDP & 2925279 & 126.24 & 18.52 & 3624391 & 133.29 & 19.63 \\
\hline & Difference & & 1.97 & & & 1.76 & \\
\hline \multirow[t]{3}{*}{ Hypertensive } & Low or no EDP & 584082 & 134.59 & 19.29 & 2687218 & 142.63 & 19.03 \\
\hline & High EDP & 1436251 & 133.51 & 18.36 & 1715006 & 141.23 & 18.19 \\
\hline & Difference & & 1.08 & & & 1.40 & \\
\hline \multirow{3}{*}{$\begin{array}{l}\text { Non- } \\
\text { hypertensive }\end{array}$} & Low or no EDP & 567713 & 121.65 & 16.09 & 2931582 & 128.10 & 18.44 \\
\hline & High EDP & 1489028 & 119.23 & 15.77 & 1909385 & 126.15 & 18.07 \\
\hline & Difference & & 2.42 & & & 1.95 & \\
\hline \multirow[t]{3}{*}{ Diabetic } & Low or no EDP & 300630 & 131.42 & 18.81 & 823959 & 138.89 & 18.75 \\
\hline & High EDP & 675920 & 130.52 & 18.09 & 515843 & 136.76 & 17.79 \\
\hline & Difference & & 0.9 & & & 2.13 & \\
\hline \multirow[t]{3}{*}{ Non-diabetic } & Low or no EDP & 851165 & 127.08 & 18.83 & 4794841 & 134.39 & 20.23 \\
\hline & High EDP & 2249359 & 124.96 & 18.46 & 3108548 & 132.71 & 19.86 \\
\hline & Difference & & 2.12 & & & 1.68 & \\
\hline
\end{tabular}

CPCSSN, Canadian Primary Care Sentinel Surveillance Network; EDP, end digit preference; RCGP, Royal College of General Practitioners; RSC, Research and Surveillance Centre; sBP, systolic blood pressure. 

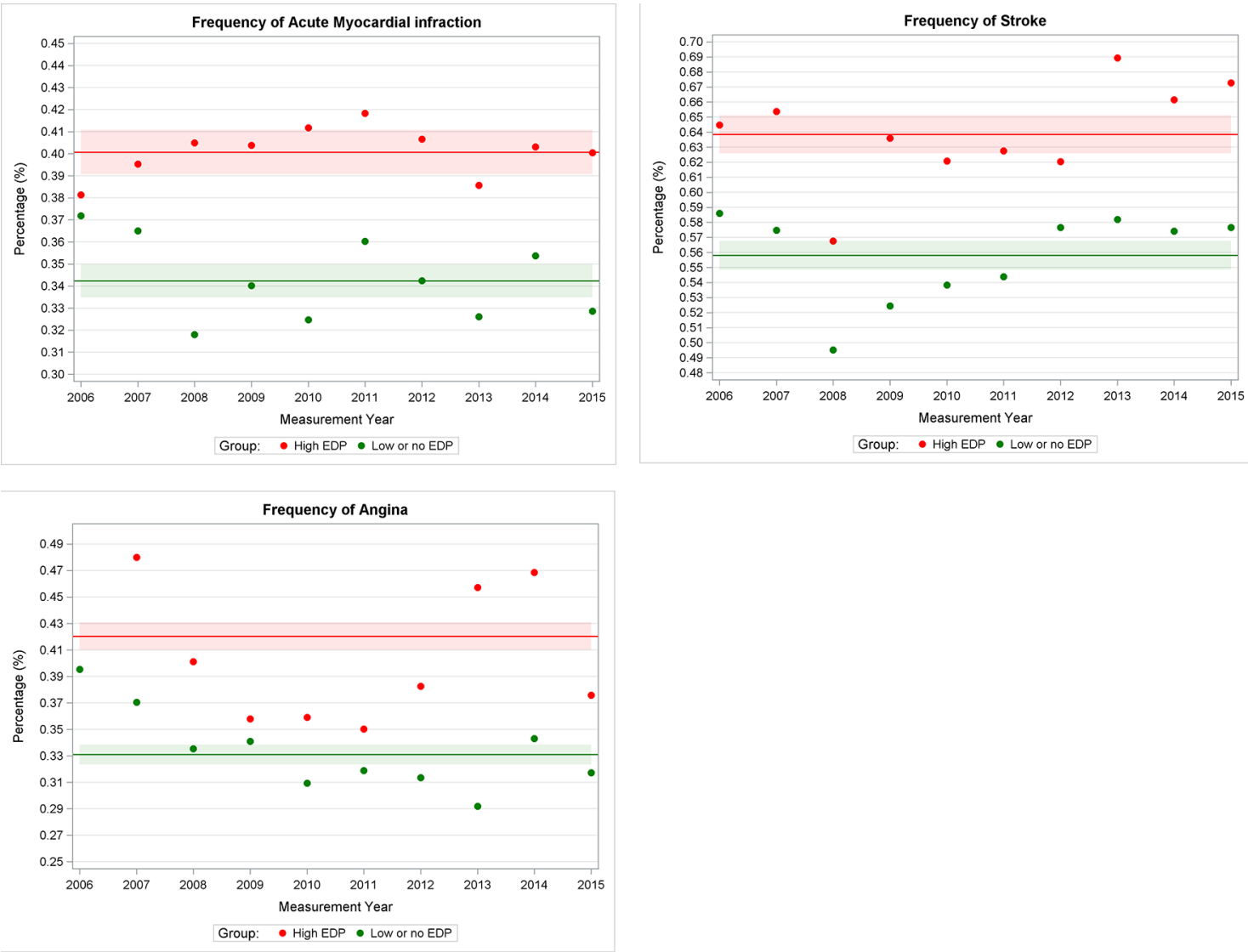

in BP from a mean of 142 to $123 \mathrm{~mm} \mathrm{Hg}$ when the initial pharmacy-based reading was elevated. ${ }^{32}$ Systematically, more accurate measurement of BP through the use of AOBP in the community, followed by notification of the primary care provider when BP was elevated, may have resulted in more treatment of elevated $\mathrm{BP}$ in primary care and decreased adverse cardiovascular outcomes.

The results in this real-world observational study in two countries are plausibly consistent with those of the CHAP RCT. We found that practices with greater precision for BP measurement (less EDP) also had a lower prevalence of adverse cardiovascular outcomes for their patients. It is possible that these practices were using AOBP more

Table 6 Standardised morbidity ratio for groups with high EDP group when compared with groups with low or no EDP

\begin{tabular}{lll}
\hline Parameter & Estimate & $\mathbf{9 5 \%} \mathbf{C l}$ \\
\hline Angina & & \\
$\quad \begin{array}{l}\text { Standardised morbidity ratio } \\
\quad 1.25\end{array}$ & 1.22 to 1.28 \\
$\begin{array}{c}\text { Acute myocardial infraction } \\
\quad \text { Standardised morbidity ratio }\end{array}$ & 1.16 & 1.14 to 1.19 \\
$\begin{array}{c}\text { Stroke } \\
\quad \text { Standardised morbidity ratio }\end{array}$ & 1.15 & 1.12 to 1.17 \\
\hline
\end{tabular}

EDP, end digit preference. often and were thus measuring BP with greater accuracy. Systematic rounding down associated with higher rates of EDP and presumably greater use of manual BP measurement by practices in this study appeared to be associated with an elevated frequency of adverse cardiovascular outcomes.

A switch to routine use of AOBP for most office-based $\mathrm{BP}$ measurements would require the purchase of enough machines to support the number of physicians and patients in each office, training of staff and healthcare providers and changes in offices processes to support more consistent use of AOBP. We are not aware of financial or other practice level incentives in either country promoting this change.

\section{LIMITATIONS}

The study has several strengths. We used data from routine community-based primary care. We also included a large sample of both patients and primary care providers from multiple settings across Canada and the UK, observed over a decade or more. Therefore, this study reasonably reflects current clinical practices for individuals receiving primary care in both countries.

This study has several shortcomings. This was a convenience sample of primary care practices that contributed EMR data to CPCSSN and the RCGP RSC. We surveyed 
practices for their use of AOBP in one network only (UTOPIAN); the survey was done at the office level rather than by physician. There may be recall bias and the actual proportion of patients whose $\mathrm{BP}$ was measured using an AOBP is unknown.

The study was not randomised; therefore, there may be unmeasured confounders associated with both higher incidence of cardiovascular outcomes and greater rates of EDP. These could include incentives or programmes that could lead to improved precision in BP measurement along with lower rates in cardiovascular outcomes, such as quality standards or funding. Our findings are associations rather than causation. Nonetheless, the differences between groups persisted as practices switched to lower rates of EDP over time and there is no a priori reason to expect a change in unmeasured confounders in practices switching to AOBP and lower rates of EDP.

\section{CONCLUSIONS}

In conclusion, systematic measurement errors including rounding down are associated with higher rates of EDP. It is likely that this is associated with more manual BP measurement in these primary care practices and in turn is correlated with a higher risk of adverse cardiovascular outcomes at a population level, although we cannot infer a causal relationship. Our findings suggest that the continued routine use of manual measurement of BP in primary care offices may be problematic. We recommend the use of AOBP as the standard of care for measuring and monitoring $\mathrm{BP}$ in medical offices.

\section{Author affiliations}

${ }^{1}$ Department of Family and Community Medicine, North York General Hospital, Toronto, Ontario, Canada

${ }^{2}$ North York General Hospital, Toronto, Ontario, Canada

${ }^{3}$ Department of Family and Community Medicine, Faculty of Medicine, University of Toronto, Toronto, Ontario, Canada

${ }^{4}$ Faculty of Medicine, University of Toronto, Toronto, Ontario, Canada

${ }^{5}$ Institute for Clinical Evaluative Sciences, Toronto, Ontario, Canada

${ }^{6}$ Department of Clinical and Experimental Medicine, University of Surrey, Guildford, UK

${ }^{7}$ Department of Family Practice, University of British Columbia, Vancouver, British Columbia, Canada

${ }^{8}$ Medical School, University of St Andrews, St Andrews, UK

${ }^{9}$ Royal College of General Practice Research and Surveillance Centre, St Andrews, UK

Acknowledgements The authors would like to thank the physicians and patients who allow data sharing for the Royal College of General Practitioners (RCGP) Research and Surveillance Centre (RSC), for UTOPIAN and for other networks participating in CPCSSN. The authors would also like to thank EMIS, In Practice Systems, TPP System0ne and other computerised medical record system vendors who collaborate with RCGP RSC to facilitate data extraction, and Apollo from the Wellbeing group for data extraction in the UK. The principal funding of RCGP RSC is Public Health England, for its work as a surveillance system.

Contributors MG, FS, SK and SdL contributed to conception and design. BA (BA) was responsible for acquisition of Canadian, and SdeL for UK data. SS was responsible for conducting the survey. SK, RM and WH contributed substantially to the analysis of data. MG and SK with input from SdeL drafted the initial version of the article. All authors, including RTV, MD and JW contributed to the interpretation of data. All authors reviewed and revised the article for important intellectual content and gave final approval of the version to be published. MG is the guarantor of this work, with SdeL for the RCGP RSC data, and, as such, had full access to all the data in the study and takes responsibility for the integrity of the data and the accuracy of the data analysis. MG had final responsibility for the decision to submit for publication.

Funding This study received funding through a grant by the North York General Hospital Foundation's Exploration Fund. MG held an investigator award from the Department of Family and Community Medicine, University of Toronto and was supported by a research stipend from North York General Hospital. The Canadian Primary Care Sentinel Surveillance Network was a committee of the College of Family Physicians of Canada and was funded through a contribution agreement with the Public Health Agency of Canada.

Disclaimer The views expressed herein do not necessarily represent the views of the Public Health Agency of Canada.

Competing interests None declared.

Patient consent for publication Not required.

Ethics approval This study was reviewed and approved by the Research Ethics Board (REB) at the University of Toronto; the survey was reviewed and approved by REBs at each participating site. REB approval was not deemed to be necessary for the UK, as no patients were identified; this was classified as a service evaluation.

Provenance and peer review Not commissioned; externally peer reviewed.

Data sharing statement Data are from a nationally representative Canadian repository of primary care EMR data, the Canadian Primary Care Sentinel Surveillance Network (http://cpcssn.ca). CPCSSN data are available to researchers as outlined in the process available on the website, cpcssn.ca. Similarly, the Royal College of General Practitioners (RCGP) Research and Surveillance Centre (RSC) network database can be accessed by researchers following the process set out at: www.rcgp.org.uk/rsc. Extra data are available by emailing michelle.greiver@nygh. on.ca.

Open access This is an open access article distributed in accordance with the Creative Commons Attribution Non Commercial (CC BY-NC 4.0) license, which permits others to distribute, remix, adapt, build upon this work non-commercially, and license their derivative works on different terms, provided the original work is properly cited, appropriate credit is given, any changes made indicated, and the use is non-commercial. See: http://creativecommons.org/licenses/by-nc/4.0/.

\section{REFERENCES}

1. World Health Organization, global health estimates. World Health Organization. Health statistics and information systems Web site. http://www.who.int/healthinfo/global_burden_disease/en/ (Accessed 29 May 2016).

2. Leung AA, Nerenberg K, Daskalopoulou SS, et al. Hypertension Canada's 2016 Canadian Hypertension Education Program guidelines for blood pressure measurement, diagnosis, assessment of risk, prevention, and treatment of hypertension. Can J Cardiol 2016;32:569-88.

3. McManus RJ, Mant J, Hull MR, et al. Does changing from mercury to electronic blood pressure measurement influence recorded blood pressure? An observational study. Br J Gen Pract 2003;53:953-6.

4. Pickering TG, Hall JE, Appel LJ, et al. Recommendations for blood pressure measurement in humans and experimental animals: Part 1: blood pressure measurement in humans: a statement for professionals from the Subcommittee of Professional and Public Education of the American Heart Association Council on High Blood Pressure Research. Hypertension 2005;45:142-61.

5. Beevers G, Lip GY, O'Brien E. ABC of hypertension: Blood pressure measurement. Part II-conventional sphygmomanometry: technique of auscultatory blood pressure measurement. BMJ 2001;322:1043-7.

6. Correa A, Hinton W, McGovern A, et al. Royal College of General Practitioners Research and Surveillance Centre (RCGP RSC) sentinel network: a cohort profile. BMJ Open 2016;6:e011092.

7. Nietert PJ, Wessell AM, Feifer C, et al. Effect of terminal digit preference on blood pressure measurement and treatment in primary care. Am J Hypertens 2006;19:147-52.

8. de Lusignan S, Belsey J, Hague N, et al. End-digit preference in blood pressure recordings of patients with ischaemic heart disease in primary care. J Hum Hypertens 2004;18:261-5.

9. Myers MG, Godwin M, Dawes M, et al. Conventional versus automated measurement of blood pressure in primary care patients with systolic hypertension: randomised parallel design controlled trial. BMJ 2011;342:d286. 
10. Myers MG. Automated blood pressure measurement in routine clinical practice. Blood Press Monit 2006;11:59-62.

11. Myers MG, Kaczorowski J, Dawes M, et al. Automated office blood pressure measurement in primary care. Can Fam Physician 2014;60:127-32.

12. Myers MG, Valdivieso M, Kiss A. Use of automated office blood pressure measurement to reduce the white coat response. $J$ Hypertens 2009;27:280-6.

13. Mancia G, Fagard R, Narkiewicz K, et al. Task Force Members. 2013 ESH/ESC Guidelines for the management of arterial hypertension: the Task Force for the management of arterial hypertension of the European Society of Hypertension (ESH) and of the European Society of Cardiology (ESC). J Hypertens 2013;31:1281-357.

14. Kaczorowski J, Myers MG, Gelfer M, et al. How do family physicians measure blood pressure in routine clinical practice? National survey of Canadian family physicians. Can Fam Physician 2017;63:e193-e199.

15. von Elm E, Altman DG, Egger M, et al. The Strengthening the Reporting of Observational Studies in Epidemiology (STROBE) Statement: guidelines for reporting observational studies. Int J Surg 2014;12:1495-9.

16. Birtwhistle R, Keshavjee K, Lambert-Lanning A, et al. Building a pan-Canadian primary care sentinel surveillance network: initial development and moving forward. J Am Board Fam Med 2009;22:412-22.

17. Primary health care intelligence: 2013 progress report of the Canadian Primary Care Sentinel Surveillance Network (CPCSSN). Kingston, Ontario: Queen's University, 2013.

18. Williamson T, Green ME, Birtwhistle R, et al. Validating the 8 CPCSSN case definitions for chronic disease surveillance in primary care database of electronic health records. Ann Fam Med 2014;12:367-72.

19. Kumar S, de Lusignan S, McGovern A et al. Ischaemic stroke, haemorrhage, and mortality in older patients with chronic kidney disease newly started on anticoagulation for atrial fibrillation: a population based study from UK primary care. BMJ 2018;360:k342.

20. Hinton W, McGovern A, Coyle R, et al. Incidence and prevalence of cardiovascular disease in English primary care: a cross-sectional and follow-up study of the Royal College of General Practitioners
(RCGP) Research and Surveillance Centre (RSC). BMJ Open 2018;8:e020282.

21. Pullenayegum EM. Multiple outputation for the analysis of longitudinal data subject to irregular observation. Stat Med 2016;35:1800-18.

22. Davison A, Hinckley D. Bootstrap methods and their application, Vol 1. Cambridge, UK: Cambridge University Press, 1997.

23. James G, Witten D, Hastie T, et al. An Introduction to Statistical Learning - with Applications in R | Gareth James | Springer. New York: Springer-Verlag New York, 2013.

24. Rencher AC. Methods of multivariate analysis: John Wiley \& Sons, 2003.

25. Campbell NR, Kaczorowski J, Lewanczuk RZ, et al. 2010 Canadian Hypertension Education Program (CHEP) recommendations: the scientific summary - an update of the 2010 theme and the science behind new CHEP recommendations. Can J Cardiol 2010;26:236-40.

26. Harrison WN, Lancashire RJ, Marshall TP. Variation in recorded blood pressure terminal digit bias in general practice. J Hum Hypertens 2008;22:163-7

27. Lusignan S, de Lusignana S, Gallagher H, et al. Audit-based education lowers systolic blood pressure in chronic kidney disease: the Quality Improvement in CKD (QICKD) trial results. Kidney Int 2013;84:609-20.

28. Alsanjari ON, de Lusignan S, van Vlymen J, et al. Trends and transient change in end-digit preference in blood pressure recording: studies of sequential and longitudinal collected primary care data. Int $J$ Clin Pract 2012;66:37-43

29. Wang $Y$, Wang $Y$, Qain $Y$, et al. Longitudinal change in enddigit preference in blood pressure recordings of patients with hypertension in primary care clinics: Minhang study. Blood Press Monit 2015;20:74-8.

30. Kahneman D, Tversky A. Prospect theory; an analysis of decision under risk. Economica 1979;47:263-91.

31. Kaczorowski J, Chambers LW, Dolovich L, et al. Improving cardiovascular health at population level: 39 community cluster randomised trial of Cardiovascular Health Awareness Program (CHAP). BMJ 2011;342:d442.

32. Ye C, Foster G, Kaczorowski J, et al. The impact of a cardiovascular health awareness program (CHAP) on reducing blood pressure: a prospective cohort study. BMC Public Health 2013;13:1230. 